\title{
ON METHODS FOR DETERMINING THE SPECIFIC HEAT CAPACITY OF STEELS
}

\author{
${ }^{1}$ Mario MACHŮ, 'L'ubomíra DROZDOVÁ, ${ }^{1}$ Bedřich SMETANA \\ ${ }^{1}$ VSB - Technical University of Ostrava, Ostrava, Czech Republic, EU, mario.machu@vsb.cz
}

https://doi.org/10.37904/metal.2021.4089

\begin{abstract}
The specific heat capacity of substances is one of the determining thermal technical properties of technical materials such as steels influencing their heating or cooling. Knowledge of their values is necessary for accurate calculations of processes such as solidification during casting in the form of continuously cast billets or ingots and during heating before forming processes or during heat treatment of finished products. The paper deals with several computational possibilities of determining the specific heat capacity of steels depending on the composition and temperature. Results are being compared with measurements using thermal analysis methods.
\end{abstract}

Keywords: Specific heat capacity, steel, properties, thermal analysis, modeling

\section{INTRODUCTION}

Modern production of steel and steel products requires precise process control during production and processing. not only due to the growing demands on product quality, but also due to the reduction of the environmental burden and financial savings in the form of energy savings [1]. Optimization of production and processing processes (casting, forming, heat treatment, etc.) work with models that require knowledge of material properties as input information. The basic thermophysical properties, the knowledge of which is crucial, include the specific heat capacity. Its values can be measured or calculated in various ways. The paper deals with selected methods of computational determination, including comparison with experimentally measured values.

\section{SPECIFIC HEAT CAPACITY}

The specific heat capacity is the amount of heat that needs to be supplied to the system to heat it by $1{ }^{\circ} \mathrm{C}(\mathrm{K})$. Its unit is $\mathrm{J} \cdot \mathrm{kg} \cdot \mathrm{K}^{-1}$. It represents a measure of the ability of substances to absorb heat [2]. Heat capacity can be calculated based on empirical rules. According to the Neumann Kopp rule, the heat capacity of a compound is equal to the sum of the molar heat capacities of the elements multiplied by the molar fractions of the elements of which it is composed [3].

$C_{p, m}^{A_{x} B_{y}}=x \cdot C_{p, m}^{A}+y \cdot C_{p, m}^{B}=x \cdot M_{A} \cdot c_{p}^{A}+y \cdot M_{b} \cdot C_{p}^{B}$

where:

$$
\begin{aligned}
& C_{p, m} \text { - molar heat specific capacity at constant pressure }\left(\mathrm{J} \cdot \mathrm{K}^{-1} \cdot \mathrm{mol}^{-1}\right) \\
& x, y \text { - molar fraction (1) } \\
& M \text { - molar weight }(\mathrm{kg} \cdot \mathrm{mol}-1)
\end{aligned}
$$

For thermodynamic calculations it is necessary to know the dependence of molar heat capacity on temperature. This is expressed by the power series. In practice, the form is often used [4]:

$C_{p, m}=a+b T+c T^{-2}+d T^{-3}$ 
where:

$C_{\mathrm{p}, \mathrm{m}}$ - molar heat specific capacity at constant pressure $\left(\mathrm{J} \cdot \mathrm{K}^{-1} \cdot \mathrm{mol}^{-1}\right)$

$a, b, c, d$ - constants based on measurements (1)

$T$ - temperature $(\mathrm{K})$

Combination of equation (1) and (2) with data valid for pure metals leads to equation (3), where specific heat capacity is a function of composition and temperature:

$c_{p}(A, t)=\sum_{i=0}^{3} \sum_{j=0}^{3} b_{i, j} \cdot A^{i} \cdot t^{j}$

where:

$$
\begin{aligned}
& A \text { - fraction of element in alloy (wt.\%) } \\
& t \text { - temperature }\left({ }^{\circ} \mathrm{C}\right)
\end{aligned}
$$

If phase transformations occur in the metal, the temperature dependence of $C_{p, m}$ is no longer continuous [5].

\section{USED METHODS}

During the experiments the specific heat capacity of 34 iron-based alloys in temperature range from 30 to $1580^{\circ} \mathrm{C}$ was measured, the range of composition is in Table 1:

Table 1 Composition of used alloys

\begin{tabular}{|c|c|c|c|c|c|c|c|c|c|c|}
\hline wt.\% & $\mathbf{C}$ & $\mathbf{N i}$ & $\mathbf{C r}$ & $\mathbf{O}$ & $\mathbf{P}$ & $\mathbf{S}$ & $\mathbf{M n}$ & $\mathbf{A l}$ & $\mathbf{C u}$ & $\mathbf{F e}$ \\
\hline $\min$ & 0.002 & 0.000 & 0.005 & 0.000 & 0.000 & 0.000 & 0.012 & 0.000 & 0.005 & balance \\
\hline $\max$ & 1.563 & 5.000 & 4.960 & 0.090 & 0.006 & 0.068 & 0.086 & 0.014 & 0.024 & balance \\
\hline average & 0.341 & 2.586 & 2.584 & 0.017 & 0.004 & 0.016 & 0.038 & 0.006 & 0.011 & balance \\
\hline
\end{tabular}

\subsection{Differential scanning calorimetry}

Thermal analysis methods are often used to obtain thermophysical and thermodynamic properties [2]. There are several techniques for measuring specific heat capacity. The most common method is differential scanning calorimetry (DSC) $[3,4]$. The term DSC is most often referred to as heat flux DSC. Both samples are located on separate temperature sensors in a common calorimetric cell. The temperature difference of the samples connected by the thermal bridge is measured (the difference between the heat flux rates into the sample and the reference, which is proportional to the temperature difference). The difference between the heat fluxes of the observed sample and the reference is measured. The first measurement is performed with an empty measured and compared crucible (blank). The second measurement is performed with a standard with a known weight and heat capacity in the measured crucible and an empty crucible being compared. The third measurement is performed with an examined sample. All measurements have the same temperature program.

The heat capacities of all analyzed alloys were observed in the temperature range of $30-1580{ }^{\circ} \mathrm{C}$ using Setaram Sensys Evo TG / DSC devices (in the range of $30-700^{\circ} \mathrm{C}$ ) and Setaram MHTC 96 line (in the temperature range of $500-1580^{\circ} \mathrm{C}$ ).

\subsection{Regression techniques}

Three methods of regression were used in this work: classic linear regression based on least square method which is well known and lies behind many empirical equations used in material engineering [7-9]. In addition two methods from machine learning area were applied on gained dataset - totally over 55 thousand samples of 34 cases (alloys). First was gaussian process regression (GPR) - a non-parametric Bayesian approach 
to regression avoiding overfitting by defining a function distribution and setting a prior distribution of unlimited possibilities over the function directly. GPR represents a generic supervised learning method designed to solve regression classification problem generalizating well due to its preference to a smooth function that accurately explains the training data without manual parameter tuning as has been the case of ANN [10]. Another advantage of using GPR is avoiding overfitting problems known from artificial neural networks [11]. Exact form of used covariance function determining the performance of model used in this work was Matérn 5/2.

Decision tree learning or induction of decision trees is one of the predictive modelling approaches used in statistics, data mining and machine learning. It uses a decision tree (as a predictive model) to go from observations about an item (represented in the branches) to conclusions about the item's target value (represented in the leaves). Tree models where the target variable can take a discrete set of values are called classification trees; in these tree structures, leaves represent class labels and branches represent conjunctions of features that lead to those class labels. Decision trees where the target variable can take continuous values (typically real numbers) are called regression trees. Decision trees are among the most popular machine learning algorithms given their intelligibility and simplicity $[12,13]$.

\section{RESULTS}

Abovementioned techniques were used to predict specific heat capacity of selected alloy. Composition of alloy is in the Table 2:

Table 2 Composition of used alloys (wt.\%)

\begin{tabular}{|c|c|c|c|c|c|c|c|c|c|}
\hline $\mathbf{C}$ & $\mathbf{N i}$ & $\mathbf{C r}$ & $\mathbf{O}$ & $\mathbf{P}$ & $\mathbf{S}$ & $\mathbf{M n}$ & $\mathbf{A l}$ & $\mathbf{C u}$ & $\mathbf{F e}$ \\
\hline 0.002 & 5.000 & 0.009 & 0.032 & 0.004 & 0.004 & 0.023 & 0.006 & 0.014 & 94.906 \\
\hline
\end{tabular}

Results were compared with measured values and with values computed by commercial software JMatPro [14] and part of in-house developed SW Tefis [15] which uses equation (3) for computation of material properties. Figure 1 and 2 show that linear regression, computation according to equation (3) (Woelk) and Gaussian process regression fails in describing in temperature ranges with phase change. JMatPro computation is significantly closer to measured values but still does not fit the peaks in apparent heat capacity caused by heat of phase change.

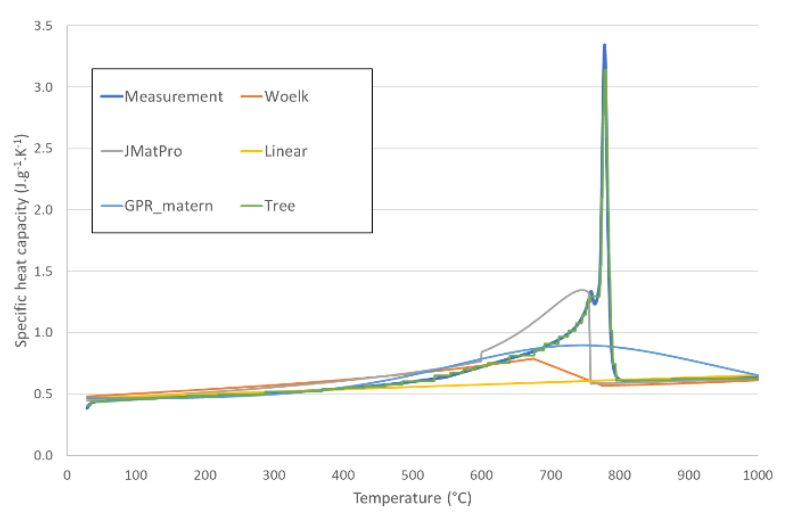

Figure 1 Comparison of various methods for $c_{p}$ determination [own]

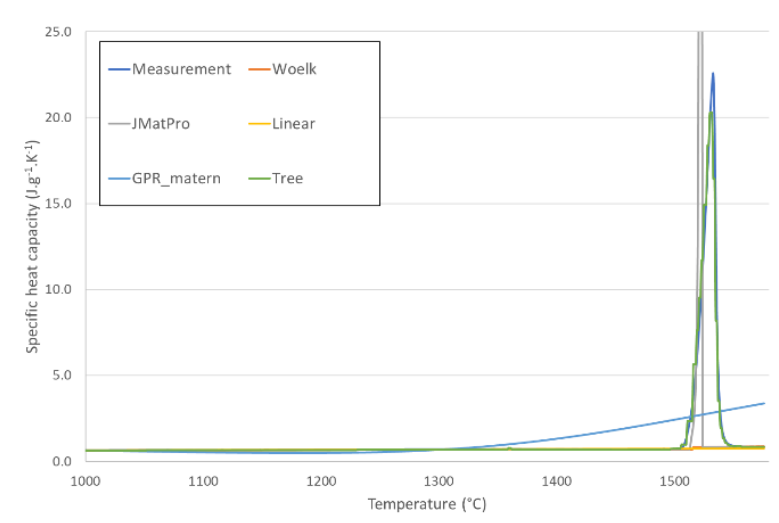

Figure 2 Comparison of various methods for $c_{p}$ determination [own]

In simulations of casting an enthalpy function (dependance on temperature) is often used [1] therefore Figures $\mathbf{3}$ and $\mathbf{4}$ show specific enthalpy depending on emperature. It can be seen that linear regression and aproach based on equation (3) falls behind the rest of presented method. The best agreement was achieved again with using of decision tree regression and JMatPro. As for the specific enthalpy, also Gaussian Process 
Regression performs well. Closer look on two best approaches shows that vast majority of predicted values of specific enthalpy by decision tree regression have an relative error up to $1 \%$ and overperforms even commercionally available SW JMat Pro (Figure 5). Plotting predicted vs. values of specific enthalpy computed from measured specific heat capacity (Figure 6) shows good performance of both selected models for further evaluation. Coefficient of determination for model based on decision tree is 0.999 , and for JMatPro model 0.995 which shows strong relation between predictions and measurement. Overal performance by means of coefficient of determination and root mean squared error of all approaches tested in this work is in Table 3.

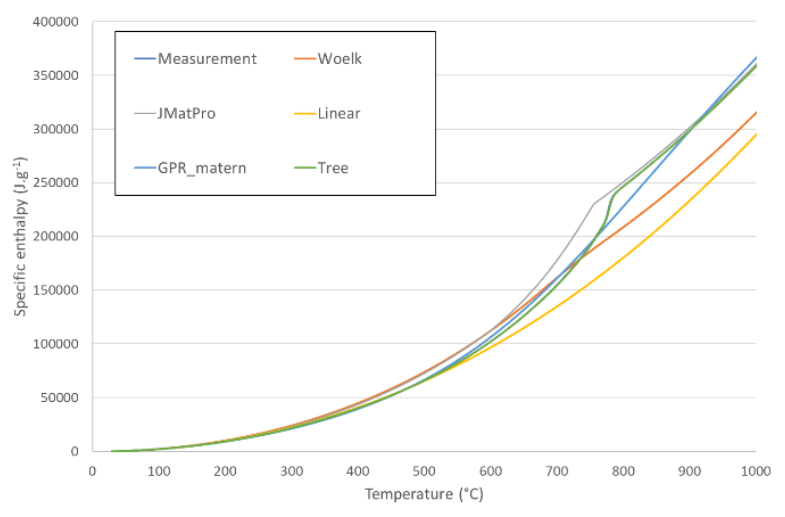

Figure 3 Comparison of various methods for specific enthalpy determination [own]

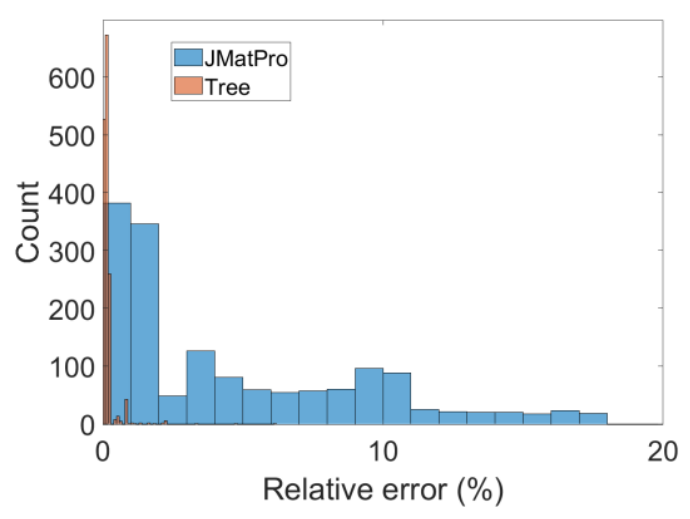

Figure 5 Relative error - predicted vs. measured values of specific enthalpy [own]

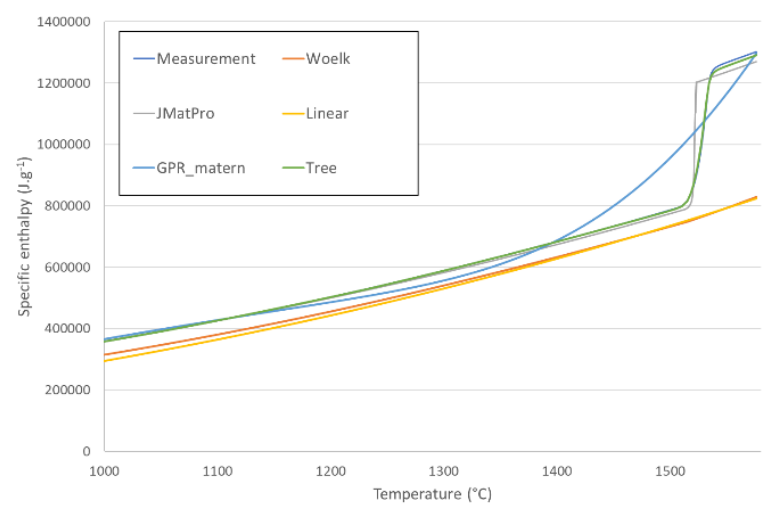

Figure 4 Comparison of various methods for $c_{p}$ determination [own]

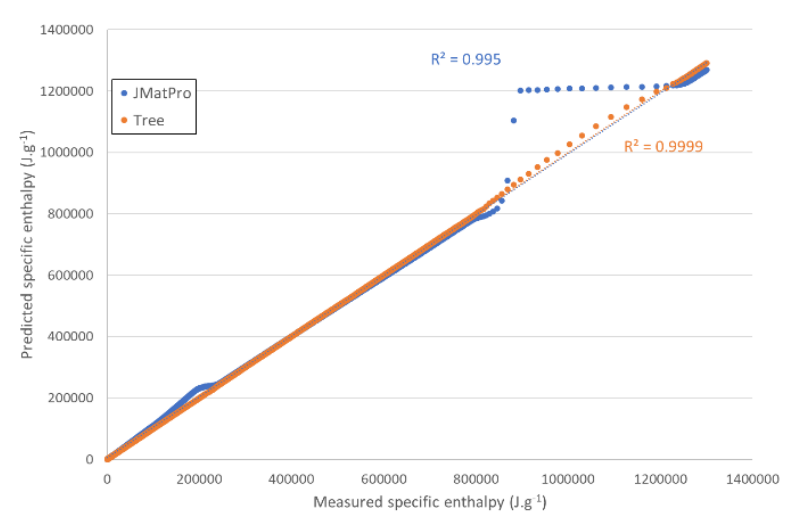

Figure 6 Comparison of selected methods for specific heat determination [own]

Table 3 Composition of used alloys (wt.\%)

\begin{tabular}{|c|c|c|c|c|c|c|}
\hline Model & Woelk & JmatPro & Linear & GPR_matern & Tree \\
\hline \multicolumn{7}{|c|}{ Specific heat capacity } \\
\hline$R^{2}$ & 0.102 & 0.05 & 0.052 & 0.167 & 0.968 \\
\hline \multicolumn{7}{|c|}{ Specific enthalpy } \\
\hline$R^{2}$ & 0.957 & 0.995 & 0.958 & 0.985 & 0.999 \\
\hline \multicolumn{7}{|c|}{ Specific heat capacity } \\
\hline RMSE & 0.1826 & 0.4252 & 0.1914 & 0.6389 & 0.0407 \\
\hline \multicolumn{7}{|c|}{ Specific enthalpy } \\
\hline
\end{tabular}




\section{CONCLUSION}

Results obtained by different approaches shows that as for specific enthalpy differences in performace almost vanish and effect of prediction failure due to underestimating or overstimating of phase change effect on values of apparent heat capacity is being smoothed. Classic approach based on weighted averaging (Woelk model), linear regression and Gaussian process regression leads to loosing information about phase transition - peaks on specific heat capacity curves are being cut off. More exact results as for $c_{p}$ gives JMatPro and especially using of decision tree method which accurately describes specific heat and enthalpy dependance on temperature. However for application where specific enthalpy is satisfactory for computation, all presented methods are suitable. Applicability of all methods is of course limited by available data for creating of a model.

\section{ACKNOWLEDGEMENTS}

\section{This paper was supported by project FW01010097 Automated systems in the field of ladle metallurgy and students projects SP2021/37, SP2021/41 and SP2021/68 (Faculty of Materials Science and Technology).}

\section{REFERENCES}

[1] KAVIČKA, František, DOBROVSKÁ, Jana, ŠTĚTINA, Josef, STRÁNSKÝ, Karel, KATOLICKÝ, Jaroslav, SEKANINA, Bohumil, HEGER, Jaromír, FRANCOVÁ, Hana. Numerical models of solidification and their application in metal and ceramic technology. Issue 1st. Brno: Brno University of Technology, Faculty of Mechanical Engineering, New Technologies for Mechanical Engineering Centre, 2016. ISBN 978-80-214-5377-7.

[2] DROZDOVÁ, L.., SMETANA, B., PRESOLY, P., NOVÁK, V., MACHU゚, M., BERNHARD, M., FRANCOVÁ, H., ZLÁ, S., ŘEHÁČKOVÁ, L., BERNHARD, C. Investigation of $\mathrm{Fe}-\mathrm{C}-\mathrm{Cr}$ and $\mathrm{Fe}-\mathrm{C}-\mathrm{Cr}-\mathrm{Ni}$-based systems with the use of DTA and HT-LSCM methods. Journal of Thermal Analysis and Calorimetry. 2020, vol. 142, no. 2, pp. 535-546.

[3] DROZDOVÁ, L., SMETANA, B., MACHŮ, M., ZLÁ, S., VONTOROVÁ, J., VÁŇOVÁ, P., ŘEHÁČKOVÁ, L., NOVÁK, V., KONEČNÁ, K., PETLÁK, D., JAHODOVÁ, K. Experimental and theoretical determination of heat capacities of model alloys based on Fe-C-Cr. In: METAL 2018 - 27th International Conference on Metallurgy and Materials, Conference Proceedings. Brno: Tanger, 2018, pp. 63-68.

[4] BARRALIS, J., MAEDER, G. Métallurgie: Métallurgie Physique, Tome I. First edition. Paris: Communications actives, 1982, 319 p. ISBN 2-85932-004-2.

[5] LAŠČEK, M. Specific heat capacity of 1Cr18Ni9 austenitic chromiumnickel steel. Acta Metallurgica Slovaca. 2008, vol. 14, no. 1, pp. 34-49.

[6] WOELK, G.: Stahl und Eisen 91, 1971, Nr 5, s. 282-286.

[7] DORESWAMY, HEMANTH, K.S., MANOHAR, M.G. Linear Regression Model for Knowledge Discovery in Engineering Materials. In: First International Conference on Artificial Intelligence, Soft Computing and Applications 2011. [online]. Available from: https://doi.org/10.5121/csit.2011.1313.

[8] SUN, Y., TU Y., SUN, J., NIU, D. Effect of temperature and composition on thermal properties of carbon steel. In: Chinese Control and Decision Conference. [online]. 2009, pp. 3756-3760. Available from: https://doi.org/10.1109/CCDC.2009.5191721.

[9] De FAOITE, D., BROWNE, D.J., STANTON, K.T. Regression analysis of temperature-dependent mechanical and thermal properties of dielectric technical ceramics. Journal of Materials Science. 2013, vol. 48, no. 1, pp. 451-461.

[10] PICHLER, P., SIMONDS, B.J., SOWARDS, J.W. et al. Measurements of thermophysical properties of solid and liquid NIST SRM 316L stainless steel. Journal of Material Science. 2020, vol. 55, pp. 4081-4093.

[11] ASANTE-OKYERE, S., SHEN, C., ZIGGAH, Y.Y., RULEGEYA, M.M., ZHU, X. Investigating the predictive performance of Gaussian process regression in evaluating reservoir porosity and permeability. Energies. 2018, vol. 11, no. 12, p. 3261.

[12] MACHŮ, M., DROZDOVÁ, L., SMETANA, B., ZIMNÝ, O., VLČEK, J. Estimation of liquidus temperatures of steel using artificial neural network approach In: METAL 2018 - 27th International Conference on Metallurgy and Materials, Conference Proceedings. Brno: Tanger, 2018, pp. 56-62. 
[13] BHOWMIK, R., SIHN, S., PACHTER, R., VERNON, J.P. Prediction of the specific heat of polymers from experimental data and machine learning methods. Polymer. 2021, vol. 220, p. 123558.

[14] WU, X., KUMAR, V., ROSS QUINLAN, J. et al. Top 10 algorithms in data mining. Knowledge and Information Systems. 2008, vol. 14, pp. 1-37.

[15] SAUNDERS, N., GUO, Z., Li, X., MIODOWNIK, A.P., SCHILLÉ, J.-Ph. Using JMatPro to model materials properties and behavior. Journal of Metals. 2003, vol. 55, no. 12, pp. 60-65.

[16] VELIČKA, M., PYSZKO, R., PŘÍHODA, M., MOLÍNEK, J. Research of heat transport in mould for continuous casting of steel. Metalurgija. 2009, vol. 48, no. 4, pp. 277-280. 